\title{
Redescribing Final Vocabularies
}

A Rortian Picture of Identity and Selfhood

\section{Mauro Santelli}

\section{(2) OpenEdition}

\section{Journals}

Electronic version

URL: http://journals.openedition.org/ejpap/1887

DOI: 10.4000/ejpap.1887

ISSN: 2036-4091

\section{Publisher}

Associazione Pragma

\section{Electronic reference}

Mauro Santelli, «Redescribing Final Vocabularies », European Journal of Pragmatism and American Philosophy [Online], XII-1 | 2020, Online since 16 June 2020, connection on 26 June 2020. URL : http:// journals.openedition.org/ejpap/1887 ; DOI : https://doi.org/10.4000/ejpap.1887

This text was automatically generated on 26 June 2020 .

\section{(c) (†) $९$}

Author retains copyright and grants the European Journal of Pragmatism and American Philosophy right of first publication with the work simultaneously licensed under a Creative Commons AttributionNonCommercial-NoDerivatives 4.0 International License. 


\title{
Redescribing Final Vocabularies
}

\author{
A Rortian Picture of Identity and Selfhood
}

\author{
Mauro Santelli
}

\section{AUTHOR'S NOTE}

I wish to thank two anonymous referees for their helpful comments and suggestions on a previous version of this paper. I would also like to thank the members of the epistemology and pragmatism groups at Sociedad Argentina de Análisis Filosófico (SADAF) coordinated by Federico Penelas, Florencia Rimoldi, Claudio Cormick and Moira Pérez (Santiago Armando, Jonathan Erenfryd, Marina Giancaspro, Anahí Grenikoff, Pedro Martínez Romagosa, Bruno Muntaabski, Daniel Pared, Alejandro Petrone and Blas Radi) for their invaluable comments when a previous version of this paper was presented in our meetings.

\section{Introduction}

1 Much has been said about Rorty's ironist, a philosophical character mostly defined by her reflective relationship with her "final vocabulary" - a set of words we employ to justify and narrate ourselves. An ironist is someone who has "radical and continuing doubts" about the final vocabulary she built while being brought up where and how she was; she doesn't think she can "underwrite or dissolve these doubts" by means of her own final vocabulary; and while in a philosophical mood, she doesn't believe her final vocabulary is "closer to reality than others." The figure of the ironist has been intensely discussed, specifically with regard to Rorty's proposal for a political rehabilitation of the "liberal ironist": a political actor committed to the tenets of liberal democracies who unflinchingly and courageously stands by those tenets while at the same time considering them contingent and unable to be neutrally defended. What's more important in this liberalization of the ironist is, for Rorty, restraining her use of her most used discursive weapon: redescription. By redescribing her own culture and 
commitments, the ironist hopes to achieve self-creation and individuality, but this same attitude, when focused on someone else's vocabularies, beliefs and hopes, can embody a destructive anti-social side - namely, what's perceived as a particularly vicious and distinct form of cruelty: humiliation. ${ }^{1}$

2 For all the discussion the figure of the liberal ironist has brought, one would think that the concept, as defined in terms of final vocabularies, would be clear and mostly accepted. I find that this is not the case. While the concept of a final vocabulary is mostly undisputed, at least in letting it sink or swim together with the concept of a liberal ironist, ${ }^{2}$ it cannot be said to be completely clear. To name several reasons: it is briefly introduced by Rorty and rarely used beyond his controversial Contingency, Irony, and Solidarity (CIS); it is no more defined beyond the use of a few examples of what could constitute a final vocabulary; and from contextual implications of the use Rorty makes of it in CIS, it's not clear why it is framed as a set of words instead of beliefs given that it stands for what characterizes a person's identity. It's also unclear exactly what relation these words may have with beliefs. And yet, it has been assumed to be an epistemic notion because ironism itself has been thought to be an epistemic (relativist or skeptical) stance (Lear 2011; Schneewind 2010; Williams 2003). Others are staunchly against this characterization and reduction of Rorty's ironism to a type of skepticism (Bernstein 2016; Ramberg 2014). While I tend to agree with the latter, ironism per se will not be my focus here.

3 Both for detractors and faithful believers, final vocabularies can seem to be merely ladders to be thrown off once one has reached their destination: ironism. I would like to argue otherwise, enlarging and working with the idea of final vocabularies to make them clearer by reweaving them alongside more accepted and explained views about personality and self-identity, both in Rorty's later philosophy and elsewhere. If I'm successful, this will make the concept look like a useful and acute description of our way of speaking about ourselves and about what's important to us. Furthermore, I claim Rorty's various reflections on the constitution of moral identity can be seen as powerful alternatives to "deep theories" of human nature (Pinker 2004; Ramberg 2014; Rorty 2004), yet, at the same time, being naturalistic through and through. Rorty, it could be argued, used different ways of talking about selves in different places for a reason: he left things vague because he didn't see a need to clarify them. I believe there is much to be gained by comparing them and reweaving them while at the same time clarifying them. Rorty's reasons do not have to be our reasons, and his tools can be repurposed. This is an exercise in redescription. In attempting this, I lay hands on concepts taken from sociolinguistics and the study of linguistic variants, on Rorty's appropriation of Daniel Dennett's metaphor that takes the I or the self as a "Center of Narrative Gravity," and - briefly - from the pragmatist theory of the formation of the self presented by George H. Mead in Mind, Self and Society. I, therefore, leave aside the problems associated with ironism and focus on the earlier step of working out what final vocabularies are supposed to be in general. Alongside the main discussion I attempt to explain why I think this concept matters today.

In order to do so, in the next section (sec. 2) I briefly present the general notion of a vocabulary in Rorty's philosophy, or what Brandom has called "the 'vocabulary' vocabulary" (2000) and some general considerations regarding Rorty's naturalism and historicism to carry into the discussion of final vocabularies of the following sections. In section 3, I reconstruct the way Rorty presents final vocabularies in CIS and compare 
it with his later approaches to personal identity and selfhood like the use of the idea of the self as constituted by narratives. One of the central questions I try to answer here is why does Rorty make final vocabularies play the central role for the constitution of identities that he does? To put it differently, why don't beliefs play that role? Why words? To try to shed some light on this point I compare Rorty's presentation of final vocabularies in the context of CIS with the way in which sociolinguists treat different linguistic variants or "lects." Before ending this section, I detail my reconstruction of the concept of "final vocabulary" and the conclusions I extracted from its analysis. Finally, in section 4, I discuss how these Rortian elements can be fruitfully brought into current discussions regarding the nature of stereotypes. I take as an example Miranda Fricker's theory of epistemic injustice and her statements to the idea of stereotypes prejudicial stereotypes - at the base of the phenomenon and attempt at sketching a more controversial answer to a different question: the question of whether the "final vocabulary" vocabulary shows any promise as a useful tool in moral discussions outside the scope of liberal ironism. I think it does.

\section{The "Vocabulary" Vocabulary and its Merits}

Before discussing what final vocabularies are, I'd like to expand on what vocabularies as such are supposed to be in Rorty's work. Rorty has both naturalist and historicist aspects interwoven in his writings. Robert Brandom epitomized this aspect of Rorty's work in his "Vocabularies of Pragmatism" (2000). On Brandom's reading of Rorty, the developing of the notion of "vocabulary" is taken to be a combined successor to the explanatory power of both "language" - in terms of structure of meanings, and "theory" - in terms of structure of beliefs. Both work in tandem as exemplars of the analytic-synthetic dichotomy, and, a fortiori, of the scheme-content dichotomy. One could argue that Rorty here is trying to be a good Davidsonian and Sellarsian and learn from the mistakes of logical empiricism. The successor concept of "vocabulary" allows us to describe both the vocabulary of the historicist and the vocabulary of the naturalist as not only non-overlapping magisteria, but also as complementary and reinforcing of each other. According to Brandom, Rorty's attack on semantic representationalism that marks his work, at least from Mirror onward, rests on the idea that representations intend to play both causal and justificatory roles. Representations are supposed to be caused by the world and justified by it. The Kantian moral that Rorty would be reminding us of is that justification is a normative concept and causation is not. The world, in the sense of extravocabulary pressures (cf. Tartaglia 2007: 214-6), can only cause beliefs, not justify them. Only beliefs can justify beliefs, because only intravocabulary relations can be considered normative.

6 To rephrase the preceding, vocabularies, in a first sense, are something attributed to others and oneself in order to explain behavior (cf. Rorty 2000b). Instead of saying that someone acts like she acts because she has this or that language, understands things in a particular way, and has this or that theory about how things work. we just attribute a vocabulary to that person. A vocabulary stands for a loose description of a social practice, with all its conceptual norms. In that social practice, words mean what they mean because people use them in certain institutionalized ways and not in others. Their mutual correction of one another engenders the norms that bind each member to a correct or incorrect usage of the words - what gives them their meaning (cf. Myers \& 
Verheggen 2016). Brandom calls this a "pragmatism about norms" (2000: 16), a position made available by the rejection of the Myth of the Given identified by Wilfrid Sellars in Empiricism and the Philosophy of Mind. A label for a position Rorty, as a good Sellarsian, exemplified throughout his career. The ways in which we use words are a function of what we believe - of what we are willing to commit ourselves to in a social setting and what we are willing to do. Since, from a Davidsonian standpoint, assertions are actions, and actions are bodily movements explainable as being caused by beliefs and desires, what something means and the beliefs one has are inseparable. One can only use words in sentences with certain illocutionary force. Only in saying something can an element of what one said, a word, have meaning. We attribute meanings and intentions by rationalizing the communicative actions of others and ourselves. In this way, vocabularies attributed to a person explain her actions in the sense of giving causes for those actions and also contain the justifications of the assertions that person makes. Rorty goes further and says that a person does not just have a vocabulary but is a vocabulary. And since a vocabulary is a social practice, a shared practice, in order to be a person, someone has to be a certain kind of person before being able to count as an individual. Being socialized, acquiring a vocabulary is just becoming a person. That is, something capable of being committed and being entitled - a someone, in short. Being someone just is being a participant in the game of giving and asking for reasons, a bearer of (inferential) rights and obligations. It is interesting to note that in "NonReductive Physicalism" (1990), a text first presented before (1987) the publication of CIS, Rorty presents "selves" as consisting of desires and beliefs, not final vocabularies. The fact that these two texts were presented around the same period further presses the question of just what the relationship between describing selves as sets of beliefs and desires and describing them as incarnated (final) vocabularies is.

7 Pushing forward Brandom's redescription of his work that Rorty himself endorses (2000c; 2010a) and what we can attribute from his endorsement of Davidsonian "metaphysics" (Rorty 1990): from a causal vocabulary, we are explainable, predictable to the degree attainable by our best natural explanations of the day. Our beliefs are physical states caused by the world (both the world inside our skins and the one outside) under a different description. The description of a historicist vocabulary in which only through being socialized as a member of a society, as an embodied instance of a shared vocabulary, can one count as believing, and not just being disposed in different ways, in the first place. Now, is there some further relationship between these two vocabularies? Brandom suggests that causal vocabularies (the vocabularies of the natural sciences) insofar as they are vocabularies, imply norms. Vocabularies, as "implicitly normative discursive practices" (Brandom 2000: 167), even the causal vocabularies, can be discussed as vocabularies:

We can ask such questions as how the vocabulary of Newtonian causes arose, and how it differs from the vocabulary of Aristotelian causes in the questions it prompts us to ask about ourselves and our activities. Rorty himself often pursues such questions, and thereby affirms his practical commitment to historicism. But developing and applying vocabularies is something that we, natural creatures, do. Our doing of it consists in the production of causally conditioned, causally efficacious performances. That is to say that using vocabularies is one among many other things that is describable in the vocabulary of causes. (Brandom 2000: 167)

Just as the vocabulary of causes is a vocabulary, the capabilities expressed in deploying or enacting a vocabulary can be described as something that a creature causally linked to its environment can do. Although Brandom does not carry the issue further in this 
piece, we can find in his earlier and later work a thorough development of this kind of relationship between genealogies of vocabularies and their causal efficacy. Rorty, in Brandom's terminology, employs a pragmatism about norms which, in turn, is a "fundamental pragmatism." A fundamental pragmatism is a metaphilosophical thesis that attributes to practical know how logical and explanatory priority over propositional know that (Brandom 2011). Applied to his pragmatism about norms, this pragmatic position opposes what he calls "regulism" (Brandom 1998: 20). Regulism is an intellectualist conception of norms in which every application of a norm presupposes an antecedently present rule that "determines what is correct by explicitly saying so" (1998: 20). Brandom takes Wittgenstein to have proven how rules, explicitly stateable principles, presuppose implicit and practical norms by showing how an intellectualist conception implies an infinite regress. Since not only actions can be correct or incorrect but also the application of the rule governing those actions can be applied correctly or incorrectly, supposing that every assessment of correctness or incorrectness implies rules to account for the correctness itself implies a vicious infinite regress of rules. This point - crucial to Brandom's conception of material inferences - is attributed to Rorty in his conception of the meta-vocabulary of vocabularies. Knowing how to follow a rule is prior to knowing that one is following a rule. Making a rule explicit is a game that can only be played if one is already a rule follower - in terms of having the social status and the accompanying capacities of an applier of norms - in a shared social practice. ${ }^{3}$ According to Brandom's use of the Hegelian distinction between norms and rules, norms are implicit and practical, and rules are explicit and propositional. They express what is implicit in a practice. That's where they derive their normative force from. ${ }^{4} \mathrm{~A}$ fundamental pragmatism, like any pragmatism about norms, is, according to Brandom, also a subject naturalism. Or a naturalism that focuses on what we do instead of on what our words refer to. Subject naturalism is opposed to object naturalism - or traditional reductive naturalism. This distinction, made by Huw Price (2011), distinguishes two different ways of understanding the relationship between philosophy and the natural sciences. Rorty (2007a) takes Price's version of naturalism as his own, and also welcomes Brandom's reading of the import of the "vocabulary" vocabulary ${ }^{5}$ (Rorty 2000c). So, to summarize this section. Rorty hammered out and used a sophisticated tool for the naturalization and historization of philosophy (cf. Ramberg 2004), Brandom's redescription of it only allows us to flesh it out and make explicit what is somehow implicit in Rorty's Wittgensteinian, Sellarsian, and Davidsonian commitments. I wish to carry forward the elements above to the discussion of the less explored notion of "final vocabularies" in the following section.

\section{Speech Communities, Moral Communities}

Rorty presents final vocabularies as follows: "a set of words which they [humans] employ to justify their actions, their beliefs, and their lives" (Rorty 1989: 73). We use these words to praise our friends and show contempt for our foes, to describe our projects, doubts and hopes. They are also "the words in which we tell, sometimes prospectively and sometimes retrospectively, the story of our lives." On one side, it is a vocabulary in that it contains words, both thin and flexible, like "right," "true," "good," "beautiful,"; and thick and more rigid words like "England," "Christ," "decency," "the Revolution," "progressive," etcetera; on the other, it is final in that we cannot justify 
these words other than by shorter or longer circles. Besides this circular recourse we can only passively give in without hope of redeeming them or defend them by force, to stand our ground. While justifying, we can't go beyond these words with language. Doubt about one's final vocabulary is doubt about one's self. ${ }^{6}$ Final vocabularies are markers for identity, we'll elaborate on this.

The relation between "final words" - words belonging to a final vocabulary - and the "platitudes" by which we justify them is a relation of expression. The platitudes, or beliefs "nobody wants to argue about" (Rorty 1989: 47), come forth when a challenge arises to one's identity. Rorty explains this point while describing common sense: ${ }^{7}$

When common sense is challenged, its adherents respond at first by generalizing and making explicit the rules of the language game they are accustomed to play

[...]. (Rorty 1989: 74)

This generalization process is the expression of the implicit relations between words of a final vocabulary, which, in this passage is tellingly named as a "language game." This implicitness is contained in the know-how needed to play the - commonsensical or otherwise - language game in which our - commonsensical or otherwise - final vocabulary is inserted. These words have meaning in their relation to other words, in a holistic manner ${ }^{8}$, just like every other word from a Davidsonian standpoint. That's why final vocabularies are sets, they display their finality as groups of words. No single word on its own could play that role, because no single word plays any role in a vacuum. So, when I take the liberty of saying "final word" I only mean a word that belongs to a final vocabulary, that word couldn't count as final on its own. Rorty goes on to say that, for a metaphysician, philosophical inquiry will tend to be an analysis of these platitudes ${ }^{9}$ or generalizations from our practice that contextually define some final words, "thin" words in particular, because they are used in almost every context.

The "platitudes" Rorty is talking about are those beliefs we take for granted and that we don't see a point in defending; what we defend with them is our final vocabularies, which, in turn, standing as their inferential articulation, constitute beliefs that are central to our self-image:

All beliefs which are central to a person's self-image are so because their presence or absence serves as a criterion for dividing good people from bad people, the sort of person one wants to be from the sort one does not want to be. (Rorty 1989: 47)

Those beliefs that are central are those that contain mostly thick (final) words, words like "progressive" or "conservative." Beliefs that instantiate these terms would be something like "being progressive is good," "being conservative is bad," such beliefs can be said to sententially (propositionally) express implicit relations between words in our vocabularies. In these cases, the way a thick word is linked with a thin word. In Rorty's view, these kinds of "platitudes" (beliefs) express "thickening" or "thinning" relations between words, since they contextually define, in our example, "good people" in terms of "something like a liberal," or condone liberals subsuming them under the - already defined in terms of exemplars - thin term "good." Central beliefs, then, are those that express the more basic moral commitments of a given final vocabulary, those that revolve around exemplars of good people and bad people - thick words mostly, and conversely, final vocabularies, are populated by words that are used when expressing beliefs implicit in our linguistic moral practices - or moral practices, period. This suggests the way in which talking about selves as constituted by beliefs and desires and talking about selves as being incarnated final vocabularies are not incompatible, but 
two ways of talking about the same thing. The question is: Why? What do final vocabularies bring to the table that beliefs and desires don't?

More has to be said about final vocabularies before we can address this question directly. It is important to note that while final vocabularies can be changed and consciously manipulated to some extent, having one is not optional, being someone and having a final vocabulary is part of the same process. Before one can have doubts about one's final vocabulary, like the ironist and the metaphysician do - in opposition to the commonsensical human, they must first have one. We are all endowed with a final vocabulary in virtue of our language and acculturation. Our "standard" final vocabulary is a final vocabulary we mostly share with others - with our "tribe," being who we are is, at least initially, more like being a certain kind of person than being a one of a kind autonomous individual. Rorty exemplifies this point regarding the doubts of the ironist:

The ironist spends her time worrying about the possibility that she has been initiated into the wrong tribe, taught to play the wrong language game. She worries that the process of socialization which turned her into a human being by giving her a language may have given her the wrong language, and so turned her into the wrong kind of human being. (Rorty 1989: 75)

Nothing can serve as a criticism of a person save another person, or of a culture save an alternative culture - for persons and cultures are, for us [ironists] incarnated vocabularies. (Rorty 1989: 80)

Having a final vocabulary is being the member of a tribe, being a tribe or culture is the use of the same final vocabulary by its members. ${ }^{10}$ Take note that I'm saying, "final vocabulary" and not just "vocabulary" while stipulating what kind of incarnated vocabulary a person or a culture is. I'd like to link final vocabularies with moral communities - in contrast with looser human groups, and selves - in contrast with mere biological individuals of the human species.

Rorty uses the term "final vocabulary" both in singular form and in the plural "final vocabularies." When using it in the plural, he does not always mean different final vocabularies of different persons, but sometimes different final vocabularies of a single person. Specifically, for instance, when we get this description of a liberal metaphysician as someone who wishes a single final vocabulary throughout her selfdescriptions, in opposition to the liberal ironist, who privatizes her constantly redescribed private self-descriptions but maintains a liberal public self-description ${ }^{11}$ :

The liberal metaphysician, by contrast [to the liberal ironist], wants a final vocabulary [...] [that] is not split down the middle by a public-private distinction [...]. (Rorty 1989: 92)

17 A split of the self, so to speak. We'll deal with this shortly, and I believe it is important, but before, a quick recapitulation: Up to this point we had selves as constituted by beliefs (Rorty 1990), and selves as incarnated vocabularies in CIS. This is brought up in the discussion of the liberal ironist: someone that-unlike the metaphysician or the commonsensical human - could be constituted as more than one final vocabulary. This is where talk of selves as sets of beliefs and desires can become particularly troublesome. It would be hard to make the liberal ironist look anything other than pathological. In what other light could we see someone that has more than one set of beliefs and desires? of course, we could always talk about someone that doesn't fall victim to her impulses and restrains herself, but this is not exactly how Rorty wanted to paint the liberal ironist. Restraining herself, in a way, is a part of what a liberal ironist 
is, but Rorty proposes a subtle liberation of the liberal ironist, he's not showing her the mast to which to tie herself. It's not mere public duty that binds her, but sincere social solidarity. Regardless of whether this last point comes across as clear or not for the time being, the splitting of the self is not a central point in CIS, Rorty expands the idea further in his career. He later makes use of Daniel Dennett's metaphor for selfhood that takes the self to be a "center of narrative gravity" (Dennett 1992). Meaning a fictional character that is narrated about by that self's brain. In simple terms: what we say of ourselves constitutes us, and what we say depends on what we do and how we justify it - and to whom. Rorty uses this way of speaking of narratives constituting the self to explain moral dilemmas, treating them not as conflicts between whimsical sentiment and hard reason, but as conflicts between "selves in dispute":

This non-Kantian view of morality can be rephrased as the claim that one's moral identity is determined by the group or groups with which one identifies - the group or groups to which one cannot be disloyal and still like oneself. Moral dilemmas are not [...] the result of a conflict between reason and sentiment but between alternative selves, [...]. Non-Kantians do not think that we have a central, true self by virtue of our membership in the human species [...]. They can, instead, agree with Daniel Dennett that a self is a center of narrative gravity. In non-traditional societies, most people have several such narratives at their disposal, and thus several different moral identities. (Rorty 2007b: 45)

18 The structure of the self Rorty describes through Dennett echoes the work of the pragmatist and social psychologist George H. Mead in which one has to be a member of a community in order to become a self (Mead 1966: 162):

The individual possesses a self only in relation to the selves of the other members of his social group; and the structure of his self expresses or reflects the general behavior pattern of this social group to which he belongs, just as does the structure of the self of every other individual belonging to this social group. [...] The process out of which the self arises is a social process which implies interaction of individuals in the group, implies the pre-existence of the group. (Mead 1966: 164)

For Mead, the self has, as a condition of its possibility, that the person become an object to itself. In a sort of linguistically inspired tone, Mead characterizes the parts of the self (a word that works as the root of all reflexive pronouns) as the "Me" (objective pronoun) and the "I" (subjective pronoun). A "Me" is an objectified self, someone in its functional role of being another to itself; the "I" is the subject proper, the role of the self that instantiates all spontaneity; it is the part of the self that enters in a relation to itself through the "Me." Only language, the use of "signifying vocal gestures" or symbols, can make this reflexive stance happen. Only through linguistic communication with others can selves happen at all. I only bring Mead to the table to signal that if he appears to get some inspiration from the analysis of the words we use to speak about ourselves ("I," "Me," "Self"), Rorty goes all the way in the linguistification of this type of theory of identity that isn't afraid to put society first and personhood last ${ }^{12}$ - and "full" personhood as only the achievement of a few particularly fortunate, skilled, and tenacious individuals. ${ }^{13}$

20 All the above notwithstanding, Rorty seems to abandon his talk about selfhood in terms of final vocabularies about the time he begins to talk of narratives around a self instead. This self may bear one or more different narratives within, and that, in turn, is a function of the several groups of people one is loyal to. This is clearly a change in perspective, but I don't believe it's a change of heart on the matter. If we look closely, the topic of group membership as shaping our moral identity already appears, quite 
centrally, even in CIS. ${ }^{14}$ Specifically, when Rorty talks about Sellarsian "we-intentions," the notion that the primitive explanatory concept for moral obligation is "to be one of us." For each group we belong to we can say: "we all want..." - as opposite to "I want...," we can formulate "we-intentions." This is a moral identity in CIS. Rorty adds to this Sellarsian view the claim that "the force of 'us' is, typically, contrastive in the sense that it contrasts with a 'they' which is also made up of human beings - the wrong sort of human beings" (Rorty 1989: 190). In sum, we-intentions typically imply and draw their force from the persons we don't want to be. Moral community between different selves, the joining together of a former "they" into a "we" depends, in CIS, on "similarities and dissimilarities" that "strike us as salient." And that salience is "a function of a historically contingent final vocabulary" (1989: 192). In Rorty's newer vocabulary we could say that it's a function of a narrative derived from a historically contingent group membership (cf. Penelas 2012; Voparil 2014). Talk of final vocabularies or narratives, I believe, is a contextual matter. Final vocabularies are only used to characterize ironism because they are a subtler tool than simpler identities require. Typical moral identities can be described more easily by talk of narratives of a self. But ironism is everything but typical. It is a meta-stable position in which selfdescription is constantly changed. Final vocabularies, by being looser than narratives (and beliefs) in the sense of not having their more fixed structure, can characterize in a more satisfactory way the constant moral restructuring the ironist inflicts on herself. A single final vocabulary can develop into several different narratives. Just by using the same important words and arranging them differently. So, final vocabularies are more stable than narratives - while still being a product of group membership. Someone who has a final vocabulary, such as someone with a certain narrative, still belongs to some group, but in a looser sense.

21 If what I'm saying is correct, having a single final vocabulary, which involves beliefs central to a person, can accommodate different narratives while still being a commonsense final vocabulary. That person, while experiencing changes, is not experiencing the profound disruption on her self-image that Rorty's ironist experiences. While the common-sense man that changes what he tells of himself with his final vocabulary may be in the process of re-shaping his loyalties, he will still be affected by the grasp of those words that connect him with the kind of people that share them. He might not use them in the same way as his peers, but he will know the way in which they use them, their use will be still a part of his divergent use. On the other hand, the ironist wishes to change not only the truth-values or the arranging of some of the words in her final vocabulary, but the truth candidates - the words and all of the semantic-pragmatic relations between them - themselves to make them her own, she does not care about their truth but about their origin. Most of us are narrators and apologists of ourselves, and as such, deal in prose; the ironist, on the other hand, deals in poetry and thrives for novel metaphors to weave into her final vocabulary. That's why narratives are too broad and rough to speak about ironism, narratives cannot capture the radical changes that Rorty wishes to ascribe to his ironist. Just as beliefs couldn't fully account for the way in which a liberal ironist could be said to have a liberal public final vocabulary and an ironist private final vocabulary without suggesting inconsistency or pathology.

After claiming, like I did, that final vocabularies and narratives are two interrelatable ways of describing the same phenomenon - both involving beliefs in one way or another, I'll take the liberty of unifying both Rortian vocabularies and speak of each moral group membership - each group membership that enables "we-intentions" or a 
talk of a "us" - as providing us not only with a narrative - or part of a narrative, but with a (lower case) final vocabulary - let's remember that final vocabularies are loosely identified as the words we use to justify (narrate, ...) ourselves. Different activities or relationships with people can demand different justificatory (narrative, ...) arsenal. In each domain in which we narrate or justify ourselves we will have a narrative and a final vocabulary that accompanies it. In different domains or groups we belong to we will typically have different narratives, but the different final vocabularies can overlap a great deal. Letting us talk, in sufficiently coherent selves, of a whole (upper case) Final Vocabulary. Our everyday moral practice evidences the degree of inconsistencies that can arise between what we say of ourselves in different domains or in different time-slices. This way of talking can accommodate the simple, and subtle, changes (consistent or not) of narrative and the profound and drastic changes of great portions of our Final Vocabulary. Changes in narrative do not imply a significant change in our Final Vocabulary, even if they rearrange it slightly, but substitution of great deals of our Final Vocabulary are bound to have drastic impacts on our narratives and justificatory practices. Such a change would imply a drastic reworking of who we take ourselves to be, what to hope, to fear and with which persons we consider ourselves related to and how.

Before going back to final vocabularies and cashing out some of the promissory notes handed out in the preceding sections, I would like to offer an analogy that can help us see the "final vocabulary" vocabulary as not just a dispensable tool for characterizing liberal ironists as not just crazy intellectuals, but as a nuanced way of speaking about ourselves. This analogy involves a brief excursus through Sociolinguistics.

\subsection{Words and Group Membership - The Case from Sociolinguistics}

Sociolinguistics is the study of the different ways that any given language varies depending on its contexts of use (cf. Llamas, Mullany \& Stockwell 2006; O'Grady, Dobrovolsky \& Katamba 1997). A language has different variants - e.g. dialects that are spoken in different geographical locations. Variants are considered such with respect to a given standard language, which is historically-politically sanctioned as such; it's less changing than its peers with lesser degrees of normalization and social prestige. To every language corresponds a linguistic community that speaks it; to each variant (including the standard variety) corresponds a speech community. Speech communities, besides the already mentioned dialects - that are individuated by geographical location - can be distinguished by a myriad of factors, from socioeconomic status, profession, gender, ethnicity and age, to any given interaction imaginable of these and other aspects. As mentioned, dialects represent the geographical variants of a language; other types of lexical, syntactical, morphological and phonological variants fall between the spectrum of sociolects and idiolects. Registers, another element involved in communication studied by sociolinguistics, refer to the contextually and intentionally defined tones and contents of communication. I will only refer to sociolects, idiolects and registers in their lexical sense. I will not address phonological, morphological or, let alone, syntactical variations.

A speaker can participate in several speech communities, and for each speech community that speaker will take part in a different sociolect that, in turn, will shape 
her stock of words, ways of pronouncing and writing them, and in some cases ways in which to arrange those words into sentences. No matter how many speech communities two speakers have in common, there will be some differences in their way of speaking. Such extreme variants, corresponding to "speech communities of one," are called idiolects. Idiolects are the thing which the individual speaker happens to forge out of her interaction with other speakers and in her involvement in different speech communities. In sum, sociolects regarded as lexical variants are words a person uses predominantly in relation to some groups, and (lexical) idiolects are words a person has in virtue of the convergence of all of her group memberships, including the membership in her community with herself, but that no other speaker has.

Before parting with sociolinguistics, we need to say a few words about registers. A "register" is a certain tone and content one employs in each communicative situation to adapt to such situation's demands and to accomplish whatever one wishes to obtain from it. Registers bring forth the different aspects of our idiolect in particular situations, such as our "technolect" (technical sociolect, or "lect" deriving from our technical competence in a field) in a job interview, or our dialect when visiting our home town, or even the part or layer of our idiolect we may adopt to chastise, congratulate or talk to ourselves (cf. Coupland 2007). To say it in Mead's words:

of course, a good deal of the self does not need to get expression. We carry on a whole series of different relationships to different people. We are one thing to one man and another thing to another. There are parts of the self which exist only for the self in relationship with itself. (Mead 1966: 142)

I want to relate Rorty's way of speaking about final vocabularies with regard to our group memberships and (upper case) Final Vocabulary regarding all our group memberships - including our membership in our community with ourselves - with sociolects and idiolects. I want to make two claims regarding this to underpin what I take to be Rorty's views: the first is rather uncontroversial: our final vocabularies are a particular subset of words of our sociolects and idiolect, the words we use to justify and narrate ourselves; the second one should look familiar by now: just as sociolects and idiolects are characterized in their relation to speech communities, final vocabularies are characterized in relation to moral communities. Sociolinguists study how our social relationships shape our way of speaking and vice versa, Rorty is interested in how what we do shapes what we tell of ourselves, our prospects and others' and vice versa. Sociolinguistics characterizes how our linguistic variants shape us as speakers; Rorty wants to characterize how our choice - limited as it might be due to our societal constraints - of words in our narratives shapes us as persons. As we have already seen, such narratives are our selfhood, and, for Rorty, every narrative about or around ${ }^{15}$ ourselves is a moral one. It is in this sense that, just as Rorty can be considered as linguistifyng a pragmatist theory of identity in which the social is primitive like Mead's social psychology, he can also be considered as moralizing sociolinguistic considerations about the relationship between speech and identity. It is this last point I want to stress in the closing section.

\subsection{Final Vocabularies Revisited}

To finish my redescription of final vocabularies, I would like to discuss what the previous means for the clarification of the importance and meaning of final vocabularies that we began with. For instance, why sets of words and not beliefs? The 
choice, as I anticipated, is between webs of beliefs and desires, narratives that commit us to certain beliefs, and words that constitute such narratives. As a good holist, beliefs on their own couldn't do the job of describing someone's identity, let alone someone as complex as the liberal ironist. Words, as we have seen in the case of sociolinguistics, are a more basic mark for group membership and identity than beliefs, they link us to greater numbers of people than beliefs do. But Rorty's choosing of words as the element out of which final vocabularies emerge gives us more than that, they are not only words used simply more than others, they are the words our narratives are constructed around, they embody group membership in a morally engaged sense. These are words we don't only use by way of our being brought up with them, but with our deliberate (yet not unconstrained), and progressive choosing of them. We not only get them like the lexical part of our sociolects, we also choose them instead of others every time we speak about ourselves. Their nodal function in narratives also permits the interplay of relative inconsistencies between different narratives or different elements in our narratives. Beliefs are too rigid and often would have to be abandoned whilst shedding narratives; words can be carried over with different workings between them, with slightly or otherwise different meanings by their context and use. It is a looser knot than the one we get with beliefs, but words tie our different narratives all the same, and even more of them while at it. Words can mark our membership in groups in similar ways as beliefs can and can also put a stronger emphasis in our relationship with people through them regardless of communion of (central) beliefs.

The distinction between thick and thin words also plays a role in this, since the thicker the words, the stronger the link with the groups that they bind us with. Thin words, by contrast, are the loose knots that could be said to bind our different final vocabularies into a single, give or take, coherent Final Vocabulary or "moral [lexical] idiolect," they make up our different moral sociolects into a single moral idiolect, capable of engaging more people than before. Thick words pull the strongest, but, Rorty claims, if we are lucky enough to live with enough security and sympathy in our midst, our thick commitments could be tamed by our contingently construed thin unifying vocabulary that would enable us to come into contact and moral communion with increasingly diverse and larger groups of people. The words we use and shape us commit us primarily with groups of people and indirectly with sets of beliefs. These groups are moral standards we live by and there is no way of saying which will win out in each conflict. Either our thin beliefs instantiated in some of our thin narratives, or our most basic beliefs that tell us which groups we are part of, who we "really" are, what (and who) we really care for. If one would like to express the link between final vocabularies and beliefs, one would have to say that they commit us to partnership in groups, some words cannot play the justifying role that final vocabularies play without one's belief that in some sense one is part of the people who say such things or act in a given way.

Final vocabularies, I would emphasize, have to be taken as sets of words and only as sets of words just because focusing on what beliefs can be abstracted from them is just missing the point of taking the trouble to talk about final vocabularies in the first place. Rorty makes this last point clear. Those words stand or fall, mostly, together. Group membership does not just endow us with a stock of words but with certain meaningful relationships between them. If I were to justify myself as a philosopher (or a spouse, or brother, or Argentinian) I would end up using a limited but interrelated set of words to say things for myself. Beyond them I could say nothing new, and while those 
relationships can vary a lot, they cannot be taken independently of each other. If I were to change my narrative, I would probably have to adjust the way I use certain words, when I use them, and for what purpose.

This is where the analogy with sociolinguistics comes in handy. While addressing moral issues it is very tempting to dispense with complexities and proclaim simple rules of behavior. This is analogous with the study of languages as abstract entities from which grammarians and grammar enthusiasts usually go prescriptive on the actual speech of actual speakers. It is no surprise that it is sometimes claimed that only competence, and not linguistic performance is the proper aim of the scientific study of languages. Performance is too particular to be studied scientifically - we can hear Aristotle saying in the background. Sociolinguistics' productive development can be taken as an argument for a more nuanced understanding of speech. A lot happens closer to the ground that can be studied and reflected upon. Max Weinreich, a famous sociolinguist, is credited as saying that "languages are dialects with an army and a navy" as a way of reminding us of the historically contingent status of our standard languages. Sociolinguists don't see the contingency of their subject as an impediment for understanding. In morality we shouldn't either. It is just this focus on particularity and the moral relevance of individuality and contingency in all its richness that talk of final vocabularies can be seen as sharing with sociolinguistics. If a toolset like the one Rorty offers us to focus on those words that we use in justificatory and narrative contexts can be put to use in order to analyze morally loaded talk, then richer interactions between macro moral theories and micro moral theories could be imagined.

It would be extremely difficult (although, I believe, not impossible) to obtain even an approximate list of words that would constitute an actual final vocabulary, but they are none the worse for that. Final vocabularies are just a theoretical relational aspect of a complex narrative about moral identity, found in different corners of Rorty's work, that was hammered out to throw some light into a difficult moral phenomenon while expressing his implicit commitments with his pragmatist and naturalist backgrounds. Not only can Rorty provide a subtler vocabulary for talking about the complex moral phenomenon he is preoccupied with but can do so without betraying his commitment to the idea that we are just clever animals.

I find this interesting because Rorty came to find the vocabulary of CIS as cumbersome and counterproductive for liberal goals. Furthermore, he openly denounced it. One need only look at his (second) debate with Nancy Fraser (2000; Rorty 2000a), here we find that Rorty talks like a universalist, he doesn't argue with Fraser from his own philosophical positions but rejoins in the vocabulary of the public intellectual apologist of the Old Left in Achieving Our Country. There is something to be learned from this. Rorty said clearly that he worried about the almost certain possibility that Democracy would fail (Rorty 1999b: 89-90). Democracy requires an engaged public, living wages and a sense of belonging (Rorty 1989: Chapter 9; 2000c; 1998b). One could argue that it is for this reason that he grew increasingly anxious about the ineffectiveness of the intellectuals and what they talked about, attempting practicing what he preached and abandoning sophisticated involvements in political matters. 


\section{On the Prospects of the "Final Vocabulary" Vocabulary of Being a Useful Tool Beyond the Scope of Ironism}

As a way of concluding this re-evaluation of final vocabularies, I would like to take this chance to speculate on how a redescription of the tools developed by Rorty in CIS, like the one I attempted above, could be used to understand other areas of current research. Miranda Fricker's Epistemic Injustice has brought to the center of epistemological discussions one aspect of the complex interrelations between epistemology and ethics. One element of her proposal involves the inescapability of stereotypes in our testimonial exchanges and assessments of credibility. Taking a middle road between reductionis $\mathrm{t}^{16}$ and non-reductionist approaches to the epistemology of testimony, Fricker proposes a view in which both the rational acceptability of testimony and the phenomenology of our testimonial exchanges is respected. The way in which she does this involves a passive critical capacity for the evaluation of testifiers' credibility that only becomes active and conscious when something goes awry. This helps Fricker concede an important point to the nonreductionists: their phenomenological point that we don't seem to notice in most testimonial exchanges making any effort to take testimony as credible or faulty - we don't seem to carry on any inference or complex process in its evaluation, while at the same time explaining the critical and rational nature of testimony. We critically, yet passively, assess a testifier's credibility in virtue of perceptual judgements informed by stereotypes of people like her. Our previous testimonial exchanges inform our present ones through the mediation of the classification of persons in stereotypes. In this way, Fricker makes abundantly clear why prejudices are so prevalent and difficult to eradicate: they are stereotypes that become immune to countervailing evidence due to emotionally faulty elements. This explains why her account is a non-ideal theory: epistemic injustice is the default state of testimonial exchanges since most of the time our stereotypes, while irreplaceable, will not be up to the task. Especially when a testimonial exchange involves disparities in power between listener and hearer. This is where testimonial injustices happen the most. We don't believe (at all, or as much) someone we should (rationally, morally) believe due to culpable prejudices we possess. Fricker goes on to explain the many ways in which epistemic injustices harm speakers (and, secondarily, hearers), both epistemically and ethically.

I believe much can be said about how Rorty can be a powerful ally in the understanding of the harms of epistemic injustice (cf. Penelas 2019), but what I want to do now is to hone in on the ways in which a better understanding of the inescapability of stereotypes (and thus prejudice) could be better understood from a Rortian picture of our moral identity, like the one I presented. An interesting question is what happens if we use the subtlety of final vocabularies to talk not about the "existential adolescent" (Rorty 2010b) who cannot help doubting her final vocabulary, but about the existentially threatened minority that isn't allowed to settle in a given description of herself. Could the description that Rorty provides about the sufferings of the culturally privileged - and also socially aware - "adolescent ironist" be of help to the culturally marginalized not by their own imaginative making? Susan Dieleman (2017) argues in favor of the usefulness of a pragmatic realism in the vein of Rorty (2000b) - where neither what others say nor The Way The World Is could make much on their own - for 
critical social epistemologies like the one Miranda Fricker presents. I believe that the subtle ways in which Rorty talks about moral identities can provide examples of just that kind of toolkit that Dieleman claims activists and social justice theorists can find useful in Rorty's work.

Another preliminary reason that is worth exploring in further work is that the link between implicit biases and words is well established in psychological research (Brownstein 2019). While biases can obviously affect how we perceive people we meet face to face through how they look, what they say, how they say it, and when they say it can play an equally important or even greater role in our prejudiced responses. Furthermore, the impact of what we read from others, without seeing them, also has been studied. For instance, talk of "woman's literature," "black literature" (cf. Fought 2006), or "gay literature" is not only applied through self-ascribed labels owing to empowering narratives, but also pervade culture through prejudicial stereotypes about themes, writing styles or registers. In sociolinguistics, as we have briefly seen, one can find an enormous trove of research into the interplays of speech and social status. In a Rortian framework this is no mystery, words are inherently and emotionally attached to persons. How we speak is a function of our upbringing and increasingly of who we want to be like, whom we try to resemble and whom we attempt to distance ourselves from. In the extreme case of the ironist this is perfectly clear, the ironist only wants to resemble herself, she can't stop redescribing what she takes herself to be in order to purge every possible influence of others from her self-image, from her identity. Ironism could have been described without an appeal to final vocabularies as words, but Rorty wanted to show how even someone who wants to be as different as possible from her peers can still retain a deep emotional attachment to them. A politically relevant attachment. By retaining the public vocabulary of liberalism, Rorty thought, ironists could be free to distance themselves as much as they could from others without promoting cruelty. This is not the place to see whether Rorty succeeded in his description of the liberal ironist and her chances of attaining autonomy without compromising responsibility and solidarity (cf. Bernstein 2016; Ramberg 2014; Rorty 2010b; Schneewind 2010; Williams 2003). Nevertheless, we can use his choice of conceptual tools for this last task in order to repurpose them in other areas where we can find cruelty and identity together, less sophisticated and common forms of cruelty notwithstanding (cf. Llanera 2016: 327-30), but also more pressing (Dieleman 2017).

The study of moral identities through the lenses of final vocabularies and identity narratives can also help stress - and make it more palatable at the same time - the point Fricker makes about the viciousness and dangers of prejudices while underscoring the inescapability of stereotypes. Stereotypes are not only inherently involved in our epistemic and moral perception of others; Rorty provides an additional argument that makes them profoundly interwoven in our very (social) constitution as selves. There is no way to be someone without first being some one. We are not only forced to see others as types of persons before knowing them for who they are as individual ${ }^{17}$ - without probably ever being able to see them only as individuals, we can't help ourselves but to see us as types of persons. Moral struggles are often described as deliberations about which kind of person we want to be. Taken to social considerations, we often hear about which society we want future generations to inherit. These are more than catch-phrases. 
If moral identities are constituted by final vocabularies, the point made by many activists of all sorts of disadvantaged groups and oppressed minorities that watch closely how we speak in order to identify unchecked biases and prejudices - and are often attacked for doing so - could be strengthened. It could be argued that it is not only a matter of political correctness, of mere courtesy and manners as it is often derided as; our choice of words involves the kind of micro-decisions that slowly shape us as better or worse people. They are also the type of choices individuals make that not only affect them and their immediate surroundings morally, they can also escalate into society-wide repercussions. Getting a better grasp of the way our choice of words shapes us and our social relations can also help shape better ways to intervene in public debates. We can understand not only why it is so important to be critical and reflexive in our ways of speaking about ourselves and others, but also why it is so difficult to effect such changes on those we find at fault - or in ourselves when others find us at fault, why so many people are so emotionally and personally involved in how they speak and why they resist so much attempts by well-meaning activists to change their forms of expression. ${ }^{18}$ How could they not be so attached? We are not only asking them to say the same thing in one way or another, we are indirectly asking them to change who they are. To change the words in which they can narrate themselves and leaving some others beyond the pale. While this is exactly what we are asking for and is being asked of us, it is easy to forget. Just as it is extremely easy to forget how hard change like the one we are demanding - or being demanded of us - can be to make, and especially all that can go wrong in the process. After all, the perils Rorty is trying to warn the ironist of are exactly those that await him behind the door of taking from someone her most cherished words and ways of narrating herself without offering anything in return. ${ }^{19}$ What we are demanding is a realignment of her loyalties, a reassessment of her affections, a profound change in habits. This kind of potential for cruelty is not only a problem for the ironist, but the radical reformer interested in producing effective change too. Or, to put it differently, final vocabularies matter not just for ironists but also for liberals not sure or particularly interested in their ironism. In this case, the problem might not be the potential of harming the target of a demand for vocabulary revision, but his resistance to such change owing to the humiliation and potential for resentment entailed. Rorty helps us see this in a more nuanced way without ever relapsing into essentialist, naively realist/representationalist (Dieleman 2017), or conformist positions considering change as just too difficult or impossible to happen.

Rorty was too quick to discard the conceptual tools he developed to talk about his elusive and maybe chimerical liberal ironist. One could argue that he did this to focus on what really matters politically, getting the intellectuals to start engaging again with questions of money and not "just" of recognition - or "love" (Rorty 1999a: 223-8). The rising tide of exclusionary nationalist movements pose a striking picture of Rorty's prescience, particularly in the US. One of the problems Rorty saw in claims for recognition is talk of cultures as intrinsically worthy of respect (Rorty 1999a: 276). The "final vocabulary" vocabulary makes it very difficult to talk that way. Final vocabularies are important insofar as they express what people find important, but one would be missing the point if one were to go and sacralize final vocabularies, what is sacred, if something is, for Rorty, is the ability to develop and enrich one's set of words, the opportunity to make them as much one's own as one has the ingenuity and desire to make them. This goes back directly to the conditions of possibility for that to 
happen, and among those conditions are affluence and security (Rorty 2000c). One can campaign for intellectuals to focus more on money and less on love, while still having a nuanced understanding of what is it to be a person in Rorty's sense. In sum, Rorty's "final vocabulary" vocabulary lets us understand the particular pain that only humans can suffer of being humiliated, of having one's identity thrown to the ground, while never forgetting that there's a lot of material work to do to expand that privilege reserved for a few.

In a world in which politics and identity are so deeply intertwined and with all the promise and dangers this entails, we need all the help we can get to understand both politics and identity as well as we can. I believe Rorty can still do a great deal for our understanding of morality and its complex relations with identity. We should not let his insights in these matters be restrained to the topic of the taming of the ironist.

\section{BIBLIOGRAPHY}

AUXIER Randall E. \& Lewis Edwin HAHN, (2010), The Philosophy of Richard Rorty, Chicago, Open Court. BERNSTEIN Richard J., (2016), Ironic Life, Cambridge, Polity Press.

BRANDOM Robert B., (1998), Making it Explicit: Reasoning, Representing, and Discursive Commitment, Cambridge/London, Harvard University Press.

BRANDOM Robert B., (2000), "Vocabularies of Pragmatism: Synthesizing Naturalism and Historicism," in Id. (ed.), Rorty and His Critics Oxford, Blackwell, 156-82.

BRANDOM Robert B., (2011), Perspectives on Pragmatism: Classical, Recent, and Contemporary, Cambridge/London, Harvard University Press.

BROWNSTEIN Michael, (2019), "Implicit Bias," in E. N. Zalta (ed.), The Stanford Encyclopedia of Philosophy (Fall), Metaphysics Research Lab, Stanford University, [plato.stanford.edu/archives/ fall2019/entries/implicit-bias/].

COUPLAND Nikolas, (2007), Style: Language Variation and Identity, Cambridge, Cambridge University Press.

DENNETT Daniel C., (1992), "The Self as a Center of Narrative Gravity," in F. S. Kessel, P. Cole \& D. L. Johnson (eds.), Self and Consciousness: Multiple Perspectives, Hillsdale, NJ, Lawrence Erlbaum.

DIElEman Susan, (2010), “Revisiting Rorty: Contributions to a Pragmatist Feminism," Hypatia, 25 (4), 891-908.

DIELEMAN Susan, (2017), “Realism, Pragmatism and Critical Social Epistemology," Pragmatism and Justice, 129-43.

FOUGHT Carmen, (2006), Language and Ethnicity, Cambridge, Cambridge University Press.

FRASER Nancy, (1990), "Solidarity or Singularity? Richard Rorty between Romanticism and Technocracy," in Alan R. Malachowski (ed.), Reading Rorty: Critical Responses to Philosophy and the Mirror of Nature (and Beyond), Oxford, Wiley-Blackwell, 303-21. 
FRASER Nancy, (1991), "From Irony to Prophecy to Politics: A Response to Richard Rorty," Michigan Quarterly Review, 30, 259-66.

FRASER Nancy, (2000), "Why Overcoming Prejudice is Not Enough: A Rejoinder to Richard Rorty," Critical Horizons, 1 (1), 21-8.

FRICKER Miranda, (2007), Epistemic Injustice: Power and the Ethics of Knowing, New York, Oxford University Press.

LEAR Jonathan, (2011), A Case for Irony, Cambridge/London, Harvard University Press.

Llamas Carmen, MUllany Louise \& Peter stockwell (2006), The Routledge Companion to Sociolinguistics, London, Routledge.

LLANERA Tracy, (2016), “Redeeming Rorty's Private-Public Distinction," Contemporary Pragmatism, 13 (3), 319-40.

MEAD George Herbert, (1966), Mind, Self, \& Society: From the Standpoint of a Social Behaviorist, Chicago, The University of Chicago Press.

MYERS Robert H. \& Claudine VERHEGGEN, (2016), Donald Davidson's Triangulation Argument: A

Philosophical Inquiry, New York, Routledge.

O'GRADY William, DOBROVOLSKY Michael \& Francis KATAMBA, (1997), Contemporary linguistics, New York, St. Martin's.

PENELAS Federico, (2012), “The Idea of Epistemic Community from the Standpoint of Rortyan Conversationalism," 11 (1), 103-13.

PENELAS Federico, (2019), "Rorty on Hermeneutical Injustice, Liberal Redescription and Utopian Imagination," ENDOXA, 43, 313-34.

PINKER Steven, (2004), “Why Nature \& Nurture Won’t Go Away,” Daedalus, 133 (4), 5-17.

PRICE Huw, (2010), “One Cheer for Representationalism?," in R. E. Auxier \& L. E. Hahn (eds.), The Philosophy of Richard Rorty, Chicago, Open Court, 269-89.

PRICE Huw, (2011), Naturalism Without Mirrors, New York, Oxford University Press.

PRICE Huw, (2013), Expressivism, Pragmatism and Representationalism, Cambridge, Cambridge University Press.

RAMBERG Bjørn, (2004), "Naturalizing Idealizations: Pragmatism and the Interpretivist Strategy," Contemporary Pragmatism, 1 (2), 1-63.

RAMBERG Bjørn, (2014), “Irony's Commitment: Rorty’s Contingency, Irony, and Solidarity,” The European Legacy, 19 (2), 144-62.

RORTY Richard, (1989), Contingency, Irony, and Solidarity, Cambridge, Cambridge University Press. RORTY Richard, (1990), “Non-Reductive Physicalism," in Id., Objectivity, Relativism, and Truth: Philosophical Papers, Cambridge, Cambridge University Press, 113-25.

RORTY Richard, (1998a), "Human Rights, Rationality, and Sentimentality," in Id., Truth and Progress, Cambridge, Cambridge University Press, 167-85.

RORTY Richard, (1998b), “Feminism and Pragmatism," in Id., Truth and Progress, Cambridge, Cambridge University Press, 202-27.

RORTY Richard, (1999a), Philosophy and Social Hope, Penguin Books. 
RORTY Richard, (1999b), Achieving Our Country: Leftist Thought in Twentieth-Century America, Harvard University Press.

RORTY Richard, (2000a), “Is ‘Cultural Recognition' a Useful Concept for Leftist Politics?," Critical Horizons, 1 (1), 7-20.

RORTY Richard, (2000b), "Response to Björn Ramberg," in R. B. Brandom (ed.), Rorty and His Critics, Malden (Mass.)-Oxford (UK), Blackwell Publishers, 370-6).

RORTY Richard, (2000c), "Response to Brandom," in R. B. Brandom (ed.), Rorty and His Critics, Malden (Mass.)-Oxford (UK), Blackwell Publishers, 183-90.

RORTY Richard, (2000d), “Universality and Truth," in R. B. Brandom (ed.), Rorty and his Critics, Malden (Mass.)-Oxford (UK), Blackwell Publishers, 1-30.

RORTY Richard, (2004), “Philosophy-Envy,” Daedalus, 133 (4), 18-24.

RORTY Richard (ed.), (2007a), "Naturalism and Quietism," in Id., Philosophy as Cultural Politics: Philosophical Papers, Cambridge, Cambridge University Press, 147-59.

RORTY Richard, (2007b), Philosophy as Cultural Politics: Philosophical Papers, Vol. 4, Cambridge, Cambridge University Press.

RORTY Richard, (2010a), "Reply to Huw Price," in R. E. Auxier \& L. E. Hahn (eds.), The Philosophy of Richard Rorty, Chicago, Open Court, 291-2.

RORTY Richard, (2010b), “Reply to J. B. Schneewind," in R. E. Auxier \& L. E. Hahn (eds.), The Philosophy of Richard Rorty, Chicago, Open Court, 506-8.

RORTY Richard \& Eduardo MENDIETA, (2006), Take Care of Freedom and Truth Will Take Care of Itself: Interviews with Richard Rorty, Standford, CA, Stanford University Press.

SCHNEEWIND Jerome B., (2010), "Rorty on Utopia and Moral Philosophy," in R. E. Auxier \& L. E. Hahn (eds.), The Philosophy of Richard Rorty, Chicago, Open Court, 479-505.

TARTAGLIA James, (2007), Routledge Philosophy GuideBook to Rorty and the Mirror of Nature (1st edition), Routledge.

VOPARIL Christopher J., (2011), "Rorty and Brandom: Pragmatism and the Ontological Priority of the Social," Pragmatism Today, 2 (1), 133-43.

VOPARIL Christopher J., (2014), “Taking Other Human Beings Seriously: Rorty's Ethics of Choice and Responsibility," Contemporary Pragmatism, 11 (1), 83-102.

WARDHAUGH Ronald, (2011), An Introduction to Sociolinguistics, John Wiley \& Sons.

WILLIAMS Michael, (2003), "Rorty on Knowledge and Truth," in C. Guignon \& D. R. Hiley (eds.) Richard Rorty, Cambridge University Press.

WITTGENSTEIN Ludwig, (1981), Remarks on the Foundation of Mathematics, John Wiley \& Sons.

\section{NOTES}

1. By resignifying others' vocabularies, the ironist ridicules them, criticizing them without offering anything in return to stand in their place - a particularly gratuitous and egregious act from a pragmatist standpoint. For the ironist cannot provide anything more real to the victim of her redescription than what's been taken from her, that is something only a metaphysician can do, 
for she, the metaphysician, does not only criticize someone else's beliefs, she shows them the truth, and in doing that she offers an alternative that fills the void of what's been taken away.

2. Arguably, this is also what Rorty does with his creation (2010b). He talks of the conflation of two sorts of people, the "unruffled pragmatist" - like Dewey - and the "existentialist adolescent" - like Sartre.

3. See (Voparil 2011) for a discussion on the limits of Rorty's reading of Brandom as aligned with his own project of putting "cultural politics" first and the role of the ontological priority of the social. The Brandomian elements used in this paper to clarify and expand upon Rorty's concept of "final vocabulary" do not depend on whether one has a Rortian reading of Brandom or a Brandomian reading of Brandom. The focus here will be Rorty's philosophy and not his disciple's. 4. In Remarks on the Foundations of Mathematics Wittgenstein states this point as follows: "One does not learn to obey a rule by first learning the use of the word 'agreement.' Rather, one learns the meaning of 'agreement' by learning to follow a rule. If you want to understand what it means 'to follow a rule,' you have already to be able to follow a rule" (Wittgenstein 1981: 405 [VII-39]).

5. Rorty also considers Price, Brandom, and himself as on the same general project in terms of anti-representationalism and naturalism (Rorty 2010a), contrary to what Price states (2010). See (Price 2013) for further elements in the Price-Brandom debate regarding the extent of the expressivism needed for a neo-pragmatist position.

6. To say it clearer, when talking about ironists, Rorty describes them as being: "[...] always aware of the contingency and fragility of their final vocabularies, and thus of their selves" (Rorty 1989: 74).

7. The three ways of relating ourselves with our final vocabularies are the aforementioned ironism, common sense: taking for granted that our final vocabulary to be sufficient to describe any person's beliefs, hopes and desires we might encounter; and "metaphyisicism": defending common sense's final vocabulary by linking it to something real and eternal.

8. One should remember to take Davidson as the background here, but Brandom can be considered to do approximately the same job. Reminding things like "the meaning of a word is the sum of the true sentences it appears in" (Davidson) and "the meaning of a word is the sum of the endorsed material inferences it takes part of" (Brandom) (paraphrasing and summarizing both views) can help.

9. Of course, an ironist's (or even a metaphysician's) final vocabulary is not commonsensical, and as such, what may be platitudinous for him may very well not be something nobody would argue but more like "nobody like that person would argue." Platitudes are those beliefs that are unneeded of argument within a shared final vocabulary or language game.

10. This has normative implications for Rorty. One can find an application of his understanding of the process of individualization as slowly and costly emerging out of socialization in his reflections on the different roles that primary, secondary and university education play in a democratic ethos (Rorty 1999a). Diversity and individuality presuppose some degree of uniformity.

11. Since shortly after the publication of CIS, Rorty's public-private divide has been profoundly controversial. Nancy Fraser $(1990 ; 1991)$ famously characterized this distinction as running against feminist breakthroughs that challenge the separation of the personal and the political. Rorty has denied these two distinctions should be lumped together (Rorty \& Mendieta 2006), but relativized the usefulness and centrality of his suggestion in CIS on other venues (Rorty 2010b). For a recent (although amiable) critique of Rorty's distinction see (Llanera 2016), for a defense of its general cogency, and usefulness to feminism see (Dieleman 2010).

12. This linguistification and turning away from a psychological theory has the merits of staying well clear of the siren's calls coming from the shallow sea plagued with coral reefs that are "deep theories" of human nature (Ramberg 2014). See also the already mentioned Voparil's take on the 
difference between Rorty and Brandom on the role of the "ontological priority of the social" (2011).

13. One can contrast this with his take about how being a woman has yet to be invented through a secluded community, Rorty (1998a) subscribes to this idea from Catharine McKinnon and Marilyn Frye.

14. And, is, of course, a staple of Rorty's philosophy since its beginnings and central on certain points of Philosophy and the Mirror of Nature (cf. Voparil 2014).

15. By "around" I mean not only direct characterizations of ourselves but also things that reflect on what we say of ourselves indirectly, like characterizing our enemies and friends.

16. Like "inferentialism" in which testimony is considered valid only if it's deemed credible in virtue of an inference, conscious or unconscious. Testimony, as such, is not an autonomous source of knowledge.

17. Ramberg (2004: 23) goes further and claims that an ideal Davidsonian interpreter would also need to assess others through the use of evidentially informed types in the process of radical or ideal interpretation. The appeal to stereotypes, from an interpretivist perspective, would not just be a defect or something we must appeal to due to our cognitive limitations, but an in-built and necessary feature of all awareness.

18. Without even getting into the complexities of linguistic change from a non-ethical perspective.

19. Even when Rorty is willing to humiliate the religious fanatic, the racist and the homophobe in the face of his descendants in class, he is offering something to them in return: an education (2000d). He is also willing to justify fighting against those that are deeply entrenched in their exclusionary ways. But he is always warning us of not making everyone our enemy, fights can be lost when numbers are not on our side and some fights are just too important to lose (cf. Rorty 1999b).

\section{ABSTRACTS}

Richard Rorty in Contingency, Irony, and Solidarity presents the character of the liberal ironist. An ironist is a person that has pressing and continuing doubts about her "final vocabulary." A final vocabulary is a set of words that one uses to justify and narrate oneself. An interesting question is why words, and not beliefs, are used by Rorty to characterize someone's identity. In this paper I take a step back from liberal ironism and focus on the notion of "final vocabulary" and its role on a Rortian picture of moral identity. In order to do this, I explore it alongside concepts from the field of sociolinguistics and from other pragmatist theories of selfhood. I claim that Rorty presents important insights for a pragmatic naturalist conception of our moral identities.

\section{AUTHOR}

\section{MAURO SANTELLI}

Universidad de Buenos Aires

msantelli[at]filo.uba.ar 